University of Louisville

ThinkIR: The University of Louisville's Institutional Repository

Electronic Theses and Dissertations

$5-2015$

\title{
The impact of victimization on the disabled.
}

Derek James Allen

University of Louisville

Follow this and additional works at: https://ir.library.louisville.edu/etd

Part of the Criminology and Criminal Justice Commons

\section{Recommended Citation}

Allen, Derek James, "The impact of victimization on the disabled." (2015). Electronic Theses and Dissertations. Paper 2160.

https://doi.org/10.18297/etd/2160

This Master's Thesis is brought to you for free and open access by ThinkIR: The University of Louisville's Institutional Repository. It has been accepted for inclusion in Electronic Theses and Dissertations by an authorized administrator of ThinkIR: The University of Louisville's Institutional Repository. This title appears here courtesy of the author, who has retained all other copyrights. For more information, please contact thinkir@louisville.edu. 


\title{
THE IMPACT OF VICTIMIZATION ON THE DISABLED
}

\author{
By
}

Derek James Allen

B.A., University of Louisville, 2012

\begin{abstract}
A Thesis
Submitted to the Faculty of the

College of Arts and Sciences of the University of Louisville in Partial Fulfillment of the Requirements for the Degree of
\end{abstract}

Master of Science in Justice Administration

\author{
Department of Justice Administration \\ University of Louisville \\ Louisville, Kentucky
}

May 2015 
Copyright 2015 by Derek James Allen

All rights reserved 

THE IMPACT OF VICTIMIZATION ON THE DISABLED

\author{
By
}

Derek James Allen

B.A., University of Louisville, 2012

A Thesis Approved on

April 16, 2015

by the following Thesis Committee:

\begin{tabular}{c}
$\begin{array}{c}\text { Richard Tewksbury } \\
\text { Thesis Director }\end{array}$ \\
\hline Thomas Hughes \\
\hline Elizabeth Mustaine
\end{tabular}




\section{DEDICATION}

Through conducting research and evaluating studies that are focused on victimizations of the disabled I would like to dedicate this thesis to two different departments. The first department is that of the Justice Administration Department. This dedication comes from the fortunate experience that I was given when I was accepted into the field. Without the knowledge of criminology, enhanced writing skills, and faculty that went above and beyond to ensure the best and most accessible education possible, this thesis opportunity may not have been possible.

The second department that is important for this thesis is the Disability Resource Center. The Disability Resource Center provides accommodations such as, accessible textbooks, upholds ADA compliance on campus, and promotes awareness of the disabled to other students on campus. The findings through this thesis is a step forward for the resource center as potentially other disabled people may find this piece useful and increase awareness of the victimization that may occur. 


\section{ACKNOWLEDGEMENTS}

As part of my journey through the graduate program it is with great pleasure that I am able to acknowledge Dr. Richard Tewksbury as my prime motivator, mentor, and encouragement to complete this thesis. His willingness to work with me through gaining accessible materials and through not only the program requirements, but through life choices, showing myself where my potential lies, and pushing me the extra step in all my endeavors to reach a high level of performance in my academics. In addition to my thesis director, I would like to thank Dr. Thomas Hughes and Dr. Elizabeth Mustaine for their consideration and gratitude for being a part of my thesis committee evaluation.

In completing this thesis it is important to recognize my wife, Lauren Allen, for her continued support from the first graduate class I started through the finish of my thesis. In addition to my wonderful wife, further motivation to finish graduate school and obtain hope in future education, was given to me by extension of my daughter, Skyler McKenzi. Without these two in my life it is undetermined if college would have been an original path for me to join. I now realize how fortunate I am to have Lauren in my life, as she was there from day one with continuous optimism with my academic career. Furthermore, family and friends have been through and around during my educational path thus far.

To my family, I want to thank my Mother, Father, and in-laws for their support, guidance, and listening to the struggles that I had encountered through gaining my 
education. Regardless of the situation there was always a positive and supportive person I was able to turn to for ideas and knowledge on potential fixtures for stressful or problematic periods of time. Also thanks to my younger brother, Nick Allen, for his encouragement and being at the University during the similar time frame as myself. Nick and I are fortunate enough to have been together for our educational experience and will graduate together as well.

To my friends that have been through this journey also deserves recognition. Nicki Lennon and I started our first semester of graduate school together and I am fortunate enough to have continued through the program with her by my side. We have collaborated, complained, and scraped through some difficult situations, but never let one another drift away. Our mirrored aspects of life brought our friendship closer and our educational achievement is something that we both admire about one another and for one another. To my friend Darren Harbour, who went to high-school, Jefferson Community and Technical College, and finished under graduate school with me also deserves acknowledgement for my accomplishments. He has been a guide to deal with certain events, an ear to listen and a shoulder to lean on when I needed it the most. Darren's continued support has helped motivate me and without his enthusiasm about my degree and opportunities, it would have been more difficult to finish successfully and I am honored for him each day.

Lastly, the final person that needs, deserves, and requires the most attention is Cliff. Cliff is my guide dog who has been with me since I started college in 2007-2008 and has never missed a class. He has overcome and found ways around construction, road closures, and spent many days riding public transportation for me to achieve my 
degree. Through wind, rain, snow, floods, and any other type of weather Cliff was by my side through it all guiding me physically and emotionally. It is important that I thank everyone above mentioned again and appreciate the consideration, guidance, and of course the love and support from my wife, family, friendships, and my visual mobility, Cliff. 


\section{ABSTRACT \\ THE IMPACT OF VICTIMIZATION ON THE DISABLED \\ Derek James Allen}

April 16, 2015

To date victimizations amongst the disabled has been researched, but the literature tends to group these victimizations amongst disabled as a whole. This research is also limited for this particular population and this review tries to outline, expand, and attempts to explain improvements for research by identifying the disabled into specific groups rather than all as one group. For example, individualizing policies and research for the blind specifically or any disability in an individualized approach. In the following an intensive online search of literature regarding different victimizations rates, types of disabilities and correlative victimizations, and the relationship these disabled individuals have with the judicial system was conducted. The findings will be discussed in the proceeding sections, using "routine activity theory" (Cohen \& Felson, 1979) to explain the victimization of the disabled and also offer policy implementations for furthering the research to individualize the material between disabilities, rather than grouping all disabled victimizations into a single category. 
TABLE OF CONTENTS

PAGE

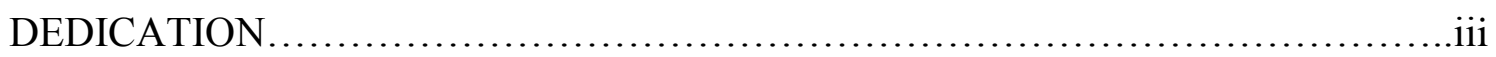

ACKNOWLEDGEMENTS .....................................................

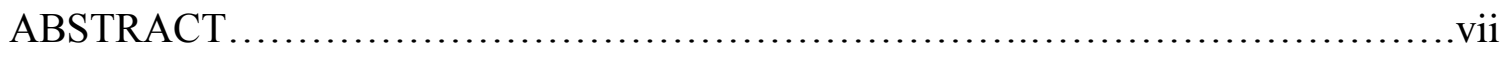

SECTION 1: INTRODUCTION ...................................................

SECTION 2: ROUTINE ACTIVITIES THEORY $\ldots \ldots \ldots \ldots \ldots \ldots \ldots \ldots \ldots \ldots \ldots . \ldots \ldots$

SECTION 3: GENERAL DISABILITIES .........................................

SECTION 4: DEAF VICTIMIZATION .......................................... 14

SECTION 5: BLIND VICTIMIZATION ...................................... 19

SECTION 6: POLICY RECOMMENDATIONS ..................................21

Policy 1: Education and Awareness..........................................21

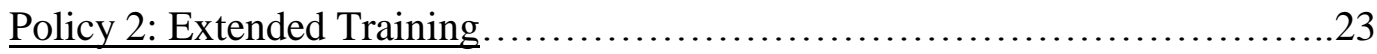

Policy 3: Increasing Guardianship .......................................26

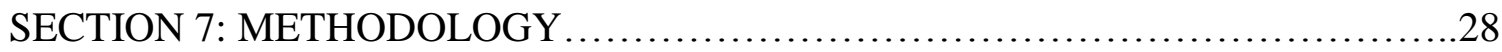

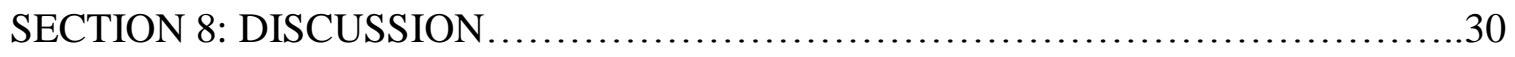

SECTION 9: CONCLUSION .................................................. 33

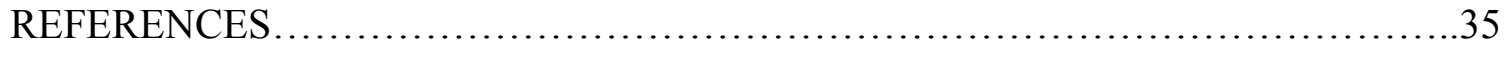

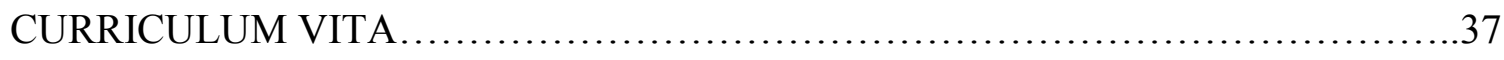




\section{CHAPTER I}

\section{SECTION 1: INTRODUCTION}

In the following there will be a discussion displaying the vulnerability of disabled individuals in society and the rates of victimization they experience. These victimizations will be criminal offenses including, but not limited to robbery, burglary, sexual assaults, simple assaults, and other crimes for which a disabled individual is more susceptible. There is also an examination of the lack of these individuals reporting their victimizations either out of fear of the perpetrator or feeling that there is not enough evidence to report. For example, a blind person who is victimized through a robbery on the street may not report this crime. The reason being, there is not a description a blind person could give the police, the direction at which the perpetrator fled is unknown, and knowing how many perpetrators were involved may be unknown to the victim. Therefore, in this example why should a blind person report this crime? There is an assumption by the victims that nothing can possibly be done to catch or convict the perpetrator. Evaluating disabled people as victims is a difficult project to approach as research is limited for most disabilities.

The following will display the limited amount of research in the area of vulnerability for the disabled population in "normal" society. Research tends to generalize (or, group together) disabilities in their studies. However, it will be argued that breaking these populations into multiple studies will benefit further research and the 
reality of differences each disability faces. For example, something that would prevent a crime to a blind individual may not work the same as it would for someone who is deaf. This is important to recognize for all researchers as recommendations and policies could be set into place for protection from the vulnerability that the disabled face in their day to day lives. In the following sections, first there will be an analysis of vulnerability amongst people who are disabled in general. These disabilities will include blind, deaf, ambulatory status, cognitive impairments, and those who need assisted living arrangements. In the following cognitive disabilities will not be addressed as there are many subsections and several broad types of cognitive impairments. Afterwards, there will be discussion of two more specifically identified disabilities and the rates at which they are targeted compared to their counter parts, the non-disabled. 


\section{CHAPTER II}

\section{SECTION 2: ROUTINE ACTIVITIES THEORY}

Through the evaluation of the following discussion routine activities theory will be the primary focus for the explanation for crimes against those who are disabled. In "routine activities theory, [it] examines the environmental context in which crimes occur. Routine activities are a theory of place, where different social actors intersect in space and time. The people we interact with, the places we travel to, and the activities we engage in influence the likelihood and distribution of criminal behavior.” (Branic, 2014)

This theory has a benefit to look at not just an individual's potential to become a victim, but also looks at populations, domains, and the other attributes of one's lifestyle. For instance, domains such as, night clubs, closed parks, or other various settings may increase the risk for an offender to find a target of vulnerability. These social gatherings in different domains can attribute to the safety of an individual and with this knowledge or awareness can influence how, where, or who you go with on certain social events. Time plays a key role as well. As mentioned, closed parks are a significant place in which a motivated offender can find a vulnerable target and lack of guardianship. This is due to the park's closure. These closures mentioned are those that are set forth by city curfews and therefore, should not be violated by the offender or the potential victim in the first place. However, in case these closures are ignored it is best to include guardianship to lessen the chances of this domain being utilized for offenders to 
potentially victimize a person. To increase the factor of guardianship larger groups is a potential deterrent for an offender due to the number of witnesses and therefore, such lowers the offender's ability to be as motivated.

In addition, routine activities theory is comprised of three main components for an offender to commit their crime of choice. These components were first introduced by Cohen and Felson in 1979 in their "Social Change and Crime Rate Trends: A Routine Activity Approach" Article. These three variables consist of "[a motivated offender, a suitable target, and lack of guardianship.]” (“(Cohen and Felson, 1979) For example, a guardian can be comprised of the number of people in a group, citizens out in the area or potential witnesses, or more officially the police. When looking to evaluate a suitable target many different things can take part for an offender to make this rational decision.

What makes an offender motivated? An offender finds motivation through the availability of a target. For example, an individual who goes to a night club alone could potentially be a suitable target for a crime at some point. This person can leave the night club and walk home, but in this situation they are alone, raising the lack of guardianship, and it is night. The atmosphere of the night setting combined with them being alone increases their chances of becoming a target for an offender. The reason an offender finds this to be profitable is because there are limited witnesses, a single target, and the ability to disguise or hide any features that may be used as describing the perpetrator to the police.

Other factors of crime rates also had a significant change during the period at which women joined the workforce in larger numbers. Furthermore, "Cohen and Felson presented data showing that, in 1960, about 30 percent of households were unoccupied by 
someone 14 years or older." This trend in absence from households is attributed to the labor force involvement. During this period of history women had joined the workforce in large numbers and therefore, turned households into vulnerable targets for burglary. This is referred to by research as a sub-section called "opportunistic" approach within routine activities theory. (Cohen and Felon,, 1979) However, "it is important to note that routine activities theory offers suggestions about the probability of criminal behavior rather than making definite claims about when crime will occur." (Branic, 2014)

This theory uses the basis of the three main components to evaluate the increase or decrease of likelihood that a crime can occur. In noting this it is important to sustain the environment as a factor, the ability to address the safety of one's' placement in a neighborhood, and also to take into account these three factors must all be presented at the perfect time; rather than randomly through space and time. Others have extended this research to define guardianship in a variety of ways. These forms of guardianships will be further explained in the following sections of specificity for a disability.

Routine activities theory is a relevant theory to evaluate the increased risk at which the disabled can potentially be victimized. Due to their physical, mental, or other classification of disability is enough to increase the likelihood for an offender to potentially be more motivated. However, this does not suggest that an offender does not find motivation to commit victimization, but the opportunity for a more susceptible target is more preferred over an individual who could identify, defend, or escape the offender's choice of victimization. This factor of being disabled is immutable for an individual and, therefore, makes them a more suitable target. "Routine activity theory stands as one of the most influential and policy-relevant theories in the field of criminology. The focus of 
this theory is on explaining the dynamics of criminal events, patterns in criminal victimization, and predictions of victimization risks/likelihood." (Cohen and Felson, 2010) Through the following discussion routine activities theory will be implemented into scenarios of the disabled to show the way being disabled impacts the chances of being a vulnerable or suitable target. This theory will also open other opportunities for policy recommendations. These recommendations will be specific to each disability as one policy will not consistently improve the likelihood that all disabilities will be protected. It is important to look at, first disabilities as a whole and secondly, there will be a description of specific disabilities, their interaction with routine activities theory, and potential policy implementations to decrease a disabled person from being a suitable target and increase the guardianship for the population as a whole and on an individual basis. 


\section{CHAPTER III}

\section{SECTION 3: GENERAL DISABILITIES}

In the following there will be a discussion to review prior research on victimization rates of disabled individuals. Through an analysis of this research there is a consistent notion that victimization rates of those people who are generally disabled are more vulnerable targets for victimization and criminal offenses. This assumption comes from the perceived lack of guardianship and vulnerability that a disabled person exhibits naturally due to their disability or, in a perpetrator's perspective their advantage for an opportunity for victimization to occur.

It is important to first understand what a disability is and secondly, to evaluate the circumstances at which victimization of this population occurs. This population of people needs "special" attention given to them for lessening the likelihood of an offense occurring. This disabled population appears physically more vulnerable to offenders, has a lack of power to defend themselves if attacked, and needs policy recommendations that promotes services that would help raise awareness of the disabled, and encourage, guide, and help the disabled victim follow through with reporting a crime.

Specifically, to be disabled the American Disabilities Act defines disability as "a physical or mental impairment that substantially limits one or more of the major life activities of such individual" (42 U.S.C. § 12102). The U.S. Equal Employment Opportunity Commission (2009) asserts that the ADA definition requires that individuals 
meet three criteria to be considered to have a disability; these include: 1) having an impairment (e.g., physiological or psychological disorder that affects body or mental processes), 2) being substantially limited (e.g., restricts an individual's ability to perform tasks the same as the general population) in 3) major life events (e.g., self-care, walking, standing, speaking, learning, and emotional/mental processes) (American Disabilities Act, 1990). Furthermore, these individuals are victimized due to their vulnerability to become a target due to their physical and mental limitations. For example, "individuals with physical, sensory, or cognitive impairments may be perceived by offenders as having higher target vulnerability (i.e., less able to resist or deter offenders \{ due to their physical or mental characteristics.\}" (Health Canada, 2004)

The conceptual frame above helps to correctly identify those who suffer from many different disabilities. For example, a physical disability refers to those individuals who have vision loss, hearing impairments, ambulatory status, and many other physical abnormalities that hinder their productivity throughout society unlike someone who does not suffer from such a disability. Others, such as mental impairments, refers to a wide variety of disabilities, but to specify a few depression, mental retardations, brain injuries, and many other varying problems associated with the brain or its' functionality. Since disabilities are broad and consist of many different types and vary in different forms the following sections will discuss some of these. More specifically, blindness and deafness will be the focused upon disabilities, as they are more predominantly known disabilities to the public.

Prior research focuses on disabilities or activity limitations as a whole to evaluate the rate at which people who is victimized. Research has been found that "In 2004, rate 
of violent victimization, including sexual assault, robbery and physical assault, was two times higher for persons with activity limitations than for persons without limitations." (Reed, 2004) For instance, "an individual with a visual impairment may be viewed by an offender as being an easier sexual assault target than someone without sight impairment." (Finkelhor and Asdigian, 1996) Next, Heidi Scherer (2011) conducted a study to determine the rate at which disabled college students were victimized compared to their non-disabled counter parts on campus for potential evidence that the victimization rates were higher for the disabled students overall.

Also, Heidi Scherer's 2011 study of disabled college students proposed that "of the twelve disabilities examined in this study were over one and a half times more likely to experience a sexual assault than students without disabilities even after controlling for other known risk factors for sexual assault." The control factors used in her study were those of race, enrollment status, grade point average, university type, mode of survey administration, binge drinking, alcohol use, marijuana use, serious drug use, number of sexual partners, fraternity/sorority membership, athletic participation, volunteers, housing, employment, relationship status, sexual orientation, and received crime prevention information (Scherer, 2011). Her findings regarding college student victimization of the disabled found that "for cognitive disorders (11.3\%), visual impairments (9.7\%), hearing impairments (9.9\%), and speech/language disorders (12.9\%) in comparison to students without disabilities (6.7\%) \{ Suffered from non-fatal victimizations.\} (Scherer, 2011) Therefore, people who are disabled and traditional students range from the ages of 18 to 23 are victimized at twice the rate of non-disabled students. 
To best explain the cause for victimization of this population is routine activities theory. This suggestion stems from the lack of guardianship that a disabled person may have. For example, independent travel on a campus setting is not uncommon for a disabled individual. In this scenario their disability incorporates the potential for becoming a vulnerable target and can be perceived as such by a motivated offender. More specifically, the lack of guardianship that a disabled person has and the setting or domain they are in can influence an offender. Therefore, by conceptually using this theory as a basis for the crimes committed on a disabled individual, there is a decrease of protection from offenders.

In addition, after reviewing the victimization rates and the offenders that were most commonly known to the victim is that of a spouse or guardian. As shown below for the disabled populations. In The Canadian Center of Justice Statistics, 2004, it is shown that "almost two thirds $(65 \%)$ of violent crimes against persons with activity limitations were committed by someone who was known to the victim. Persons with activity limitations were 2 to 3 times more likely to be victims of the most severe forms of spousal violence, such as being sexually assaulted, beaten, struck or threatened with a weapon." In addition to the Canadian Activities Limitation survey the Bureau of Justice Statistics reports that as of 2010 "Persons with disabilities are more likely than general crime victims to be victimized by someone they know, and less likely to be targeted by strangers.” Also, “\{overall\} $33.4 \%$ of disabled people report an injury requiring medical attention as a result of their violent victimizations, compared to only $27.7 \%$ of nondisabled persons." (BJS, 2010) Through looking at these two situations combined it is generally consistent between the two separate regions with the same results. What makes 
the disabled more vulnerable to the people they know or, potentially even a caretaker for the individual?

Further, data from the Participation and Activity Limitation Survey has shown, "that persons with disabilities experienced higher rates of unemployment and lower median family incomes." and therefore, is correlated to the notion that "reasons that persons with a disability are less likely than those without a disability to report their victimization incidents to the police. Among the possible explanations, persons with disabilities might fear losing their financial security, their housing or their welfare benefits when the perpetrator in question is a person they know. In addition, the victims might fear they will not be believed or will be perceived as not credible by the police or the courts, or that there will not be appropriate services." (OVC, 2005, 2009 Health Canada, 2004, 1993) Other research has demonstrated that "only $39.1 \%$ of disabled persons reported a robbery to police, compared to 63.1 percent for all others. Only $40.3 \%$ of disabled persons reported an aggravated assault to police, compared with $64.4 \%$ of all others." (BJS, 2010) These results are consistent with the under-reporting of crimes amongst the disabled by two times less than the average person in a similar situation. The reasons for this possibility are correlated with the notion mentioned above regarding their personal situations, living arrangements, and financial support or dependence upon the potential perpetrator.

When a victim who is being victimized by someone they know, there is a higher possibility that the person who is disabled needs them for financial support, assistive living arrangements, or shares a commonality that would suggest higher spousal violence within the home. The reason for spousal increases in violence potentially comes from the 
fear of reporting the violence due to the possibility of losing a place of residence, income, or many other societal variables such as, if there are children involved in the home, or other family members that could be impacted from the report.

In regards to those who do not feel confident in reporting to the police due to their disability, there is a strong notion that if the perpetrator is unknown to the victim the disability could hinder one's ability to report the crime. For example, if a deaf individual is robbed on the streets and did not hear the subject's voice, hear the direction they came from, or identify the race of the perpetrator; this limits the information the police to follow through with in an investigation. A further example of a blind individual being assaulted by a stranger could bring doubt to the victim in reporting the crime. These aspects that a blind individual needs to report could be hindered simply due to their vision loss. To further explain, in a blind person's situation there is no description of the perpetrator, potentially no account of the direction they came from or fled to, and most importantly any demographic information to match a perpetrator to the crime. Therefore, in these two examples, there is a lessened chance for reporting crimes to their local authorities. For these two disabilities victims may feel that firstly, they have not enough information to change the situation, and secondly, there is an aspect of embarrassment of being attacked with knowing nothing except the situation happened and where it happened. The facts that would lead to an arrest are missing entirely and therefore, push a motivated offender to target the disabled because of their limitations. Policy recommendations for police officials and law enforcement will be addressed in the continuing sections below. 
In the next section there will be an analysis of victimization amongst the deaf population. This population is one of many disabilities in which victimization occurs, but is rarely studied, addressed legally, or reported to law agencies. These reasons are outlined above, but will be more detailed throughout the next section. 


\section{CHAPTER IV}

\section{SECTION 4: DEAF VICTIMIZATION}

In the proceeding section there will be a specific discussion regarding victimization amongst the deaf population. Deafness is a disability in which a person has a severe impairment in hearing. This subsection of the population is important to mention as they are more commonly seen, known, and more independent in their daily living than other disabilities. This independence therefore, allows for this population to be more integrated into the general public and potentially a higher risk for victimization simultaneously.

“According to data from the 2010 Survey of Income and Program Participation (SIPP), approximately 7.6 million people ages 15 and older in the United States have difficulty hearing, while approximately 1.1 million of these individuals define their hearing difficulty as severe. In the SIPP questionnaire, difficulty hearing was defined as experiencing deafness or having difficulty hearing a normal conversation, even when wearing a hearing aid. Those who were deaf or unable to hear a normal conversation were described as having a severe difficulty.” (SIPP, 2010) This is a significant population size and therefore, is more concerning when victimization rates are evaluated for the deaf community. Unfortunately, there is a limited amount of research that directly distinguishes victimization between those who suffer from deafness compared to disabled in general. However, the research that has been conducted does suggest an interpretation to the likelihood that there are victimization rates amongst the deaf that is significant for 
further evaluation and analysis. Below will demonstrate studies and their findings that will appear to have a consistency in victimizations on the deaf.

"Using survey data comparing almost 1,900 students at the Rochester Institute of Technology and the National Technical Institute for the Deaf, researchers found that Deaf and hard of hearing individuals were 1.5 times more likely to be victims of sexual harassment, sexual assault, psychological abuse, and physical abuse than their hearing counterparts." (Smith \& Hope, 2015) Through evaluating the results of this study there is a relevant importance to figure out why deaf individuals are one and half times more likely to be victimized. There is a notion that this population is more vulnerable to be victimized due to their physical disability and experience a lack of services to report crimes. For example, if a deaf person were to be attacked or sexually assaulted the masking of a face for a perpetrator would be all that is necessary for a victimization to occur on a deaf individual. In this situation there is limited information to give to the police and before obtaining the ability to report the crime occurrence there is a language barrier between the deaf person and the police officer. This can therefore, initialize further embarrassment to report a crime as an interpreter must be found, the story needs to be told to the interpreter, and then to the police officer.

Furthermore, a study that demonstrates the difference between a victimization rate of those females who are deaf and their non-deaf counterparts found that "According to a 2011 study examining intimate partner violence among 100 Deaf female undergraduates, approximately twice as many deaf respondents reported experiencing intimate partner violence in the past year than their hearing counterparts." (Smith \& Hope, 2015) Non-fatal crimes against the deaf appear consistent in these individual 
research findings. But more commonly between the studies is the victimization of sexual assault or rape. These two types of victimization both appear to be potentially the most concerning violent crime against the deaf population.

Next, is a study that was conducted to evaluate the difference between deaf and non-deaf victimization for adults in general. "A 2014 study found that deaf adults were more likely to experience forced sexual experiences than hearing adults. Deaf survey respondents experienced forced sexual incidents at rates that were at least twice those reported by hearing respondents in other surveys." (Smith \& Hope, 2015) These victimization reports also are focused towards that of sexual assault on the deaf individuals and at twice the rate of their counter parts. This victimization does not specify the settings or those who committed the victimizations, but as previously mentioned, the deaf population is more integrated into society in terms of being known to people, using regular or normal forms of daily living like their counter parts, and generally are more available throughout society compared to other disabilities that are institutionalized, unable to communicate with the general population, or, cannot independently go from one place to another.

Lastly, the Bureau of Justice Statistics reported that as of 2010 "violent victimization rates were 8.3 per 100,000 deaf persons, simple assaults were reported as 4.8 per 100,000 persons, and rape victimization rates are too low to calculate." It is important to note that although rape victimizations are too low to calculate, this is an under reported crime for the general public. In comparison violent assaults are twice as high as those of simple assaults. This is potentially due to the previous mentioned report, in Section 3, from the Bureau that states "Violent victimizations against all three 
disability groups, \{deaf, blind, and ambulatory\} are more likely to include a weapon, including gun, knife, and any other type of weapon." (BJS, 2010) Looking at the results from the Bureau of Justice Statistics, the deaf population is broken down into victimizations amongst males and females. These rates are as follows, for "males 8.9 per 100,000 reported victimizations and for females 7.5 per 100,000 victimizations" (BJS, 2010). These findings appear to be small when looking at the statistics, but the limited amount of research that has been conducted and under reporting of crimes potentially signifies these rates to be much lower than they are in reality. What is the best explanation for victimization of the deaf?

There is an application of routine activities theory to explain this unfortunate violence against the deaf population. Using the routine activity theories model and the three main components; those being a motivated offender, a suitable target, and lack of guardianship, we can see an explanation for this increased likelihood of victimization. In this instance a deaf person, male or female, is automatically a suitable or vulnerable target due to their inability to hear their surroundings. For instance, a deaf person is coming home from a party late at night. This opens for two discussions. First, the deaf individual is alone at night and secondly, is suffering from the deafness. This inability to hear the surroundings of the environment leaves it easier for an offender to be motivated to "sneak" up on a deaf person for an optimal advantage of surprise. This deafness is also correlated to the lack of guardianship in physical ability. The lack of guardianship can be replaced with an individual who can hear their surroundings. For example, if the person mentioned above did not suffer from a hearing impairment they would be able to hear someone who is creeping up on them for an attack. Just the ability to hear is enough to 
increase the guardianship component. This makes the individual less susceptible for an attack, due to the hearing component not being an issue in the first place.

Concluding this section on the deaf it is apparent that further research needs to be conducted for more reflective statistics on the deaf population. Victimization rates from the above mentioned studies that have been conducted explore information that is valid, but not necessarily generalizable for the deaf, as research has been limited. However, the research that has been conducted does signify that there are potential problems with violence against the deaf population. In the proceeding section, an outline of another specific population, the blind, will be evaluated for victimization rates and other important factors regarding research, reports of victimization, and problems through the legal processes. 


\section{CHAPTER V}

\section{SECTION 5: BLIND VICTIMIZATION}

In the proceeding discussion rates of victimization will be analyzed, explained, and evaluated for the blind population. Through this analysis rates of victimization will also be shown through examples to conceptually understand what makes a blind individual more susceptible for victimization. The blind population, like the previously mentioned deaf population, is also well integrated into regular society. For example, a blind person has the independence to travel, interact, and accomplish tasks such as, employment and post secondary education with little accommodation. Blind, visually impaired, and legally blind are terms used to define the differences in a person's vision. For instance, blind is equal to no vision, but may include the ability to see light. The terms "legally blind" and "visually impaired" are commonly used interchangeably; this

consists of a visual acuity of 20/200. The victimization rates for the blind population are important to acknowledge compared to those who are not blind.

Through looking at the Bureau Justice of Statistics from 2010, " $\{$ the blind suffer from violent assaults 15.1 persons per 100,000.” Blind individuals are susceptible to simple assaults "7.1 per 100,000 persons." (BJS, 2010) Like the deaf population, the rates at which this population suffers from rape or sexual assaults are too small to calculate. 
We return again to Scherer's (2010) study conducted on college participants and her results that the blind were " $9.7 \%$ more likely to be a victim compared to their college counterparts.\}" This study had also presented the knowledge that the disabled were twice as likely comparatively to be victimized. To interpret these findings from Scherer and the Bureau Justice of Statistics it is important to recognize the ability at which this group is also a population with higher vulnerability.

This vulnerability comes potentially from the simple fact that a blind person cannot see their attacker. For example, in an assault, robbery, or other victimizations a blind person has no chance to give a description of the offender. To the knowledge of the blind person they only may have a description of whether their attacker was a female or male by the sound of their voice. Another example relates to a sexual offense occurring. The blind are perfect targets for those sex offenders registered online or through their notification requirements in their own states. The reason for a blind person to be a perfect target is due to the fact that they cannot look at the photographs distributed to them through the sex offender registry, nor have the initial ability to describe the offender. This lack of the ability to see hinders the victim and potentially increases sexual predators to seek out this population. In this situation guardianship is severely decreased as the person cannot see therefore resulting in a more motivated offenders presence. 


\section{CHAPTER VI}

\section{SECTION 6: POLICY RECOMMENDATIONS}

In this section policies will be discussed based on the research that has been conducted and reviewed. These policies are education/awareness, extensive training through the workforce, and increasing the guardianship available to a disabled person. These policies are recommended due to previous information that discusses the lack of reporting victimizations, the inability to strengthen ones guardianship, and to inform those who work in the judicial sector, law enforcement, and victim/crisis advocates with their communication and awareness for individualized treatment of the victim. The policies outlined below are structured for those people who are disabled in general and will also encompass suggestions more specific disabilities.

This section will promote policy recommendations to decrease the chances of a disabled person being targeted due to their potential vulnerability. These policies that will be introduced will consist of policies in regards to those who are disabled in general, policy evaluation for specific persons or type of disability, and a general overview of accomplishments that the policies may provide.

\section{Policy 1: Education and Awareness}

First, this policy recommendation is primarily for those disabled individuals of any kind in society. It is important to educate the disabled on crime prevention, awareness, and reporting to law enforcement. The mechanisms by which to provide 
educational material can come to the disabled through different modes of services that the disabled interact with on regular basis.

To further explain, educational brochures promoting crisis stabilization units, information involving types of victimizations, how to report, and where to find therapeutic treatment if necessary can be displayed accordingly. In these brochures of information specific things should be targeted to generalize for everyone. For example, telephone numbers to gain access to a crime stabilization unit, also referred to as Rape Crisis Centers or mental agencies help hotlines, further online information, and factual information such as, number of victimizations last recorded against the disabled can be listed. This last suggestion is to promote and encourage the disabled to report their victimization because they are not alone according to the statistical review outlined in the brochure and in Section 1. The following places and groups to distribute this educational material are some, but not all of the outlets by which the disabled can be reached:

The Social Security Administration's offices offer potential that those who are disabled will see this material; as this office is the primary office by which individuals can gain assistance financially when disabled and unable to work. The next place in which the disabled can be targeted is through activist groups distributing educational material. These activist groups are more concentrated to specific disabilities for example, The National Federation for the Blind, The National Association of the Deaf, or extending the literature to the Paralyzed Veterans Association.

In addition, for therapeutic and mental health purposes these brochures can be placed in mental health agencies as additional material for parents, family, and guardians to receive for reference. This would be especially useful in those centers that are income 
based; as noted in Section 1, there is a high volume of the disabled that are on the low economic spectrum. Through reaching out to these individualized groups of activists, mental health agencies, and federally or state funded programs that assist the disabled there is further potential for "word of mouth" and possible sharing of this education awareness to sister activists and mental health agencies groups for many different disabilities. The next policy will focus more on training and awareness amongst responding officials. For example, Rape Crisis Centers, law enforcement, and judicial staff training are the policies main focus.

\section{Policy 2: Extended Training}

Initial and additional training is something that is a part of most of the agencies by which this policy recommendation is directed towards and therefore, can be implemented easily to the staff training sessions. For Rape Crisis Centers, mental health agencies, and judicial representatives this training is consistently changing, improving, and there is always new information that needs implemented into the training sessions. Therefore, it is important for these individuals to introduce diversity training, if it is not already a part of their regular training sessions. This diversity portion is a base line for working amongst a diverse population.

This base for training diversity to the employees of these agencies is necessary for working with people of different cultures, ethnicities, disabilities, and many other factors that are individualized from person to person. Once this diversity training has displayed the importance of working with these populations there should be a more specific and detailed section of material that could be introduced to the employers training. 
Through this more in depth training communication skills, patience, and time will be important for staff to know. This information should be delivered by someone who is trained in disabilities, or works with the disabled on a regular basis. For example, an adult rehabilitation center for adults to adapt to their disability could send a representative to distribute this material. The material involved in this presentation should be outlined and physical hard copies of information should be delivered to all participants in the training. This material that is given out should also be presented interactively with the staff for confirmation of the staff understanding new ideas and methods of working with this particular population.

This more direct approach to outlining the above mentioned groups is helpful by breaking the populations down into individual persons; rather than groups of people. For example, a rape crisis center can be trained to work with a blind individual to cope with a victimization that has occurred. Working with the deaf for example might allow and facilitate TTY telephone services available to these individuals. Further training amongst law enforcement and judicial members is also of high importance.

This importance of training the judicial sector and law enforcement is necessary for the victim and also important for the victim advocate and law enforcement officers due to the nature of the crime and the person involved. In doing the training for these individuals it promotes, teaches, and explains how to interact with a blind, deaf, or other disabled individual on a level of communicative skills. For example, a blind person does not require raising your voice when approached into a conversation. Likewise, when interacting with a deaf individual it should not be assumed that he or she can read lips. For a lip reader it is still difficult to catch a full conversation and therefore, an 
interpretation is important for these situations that deal with a lawyer, victim advocate, or others in law enforcement.

In evaluating the solvability of a disabled persons victimization the above mentioned material that has been presented through the trainings is a base line for understanding. Using the patience, communication skills learned, and different methods of interaction between different disabilities this may raise solvability of some cases. However, currently solvability is difficult for law enforcement because, of the under reporting of crimes by the disabled. Parallel with the under reporting is the problem of figuring out enough details for law enforcement to solve a crime. However, drawing emphasis to the skills and training of diverse populations and specifically those skills to communicate, aid, and be patient with a disabled person could increase the reporting and solvability for the disabled.

Concluding this policy implementation, the basic approach is to introduce the workforce that relates with the judicial sector, law enforcement, and other crisis services with more specified information about the disabled. In diversity training it is easy to explain religious, sexual orientation, and other differences people have in generalized definitions. However, with the disabled there are a few extra details that need to be addressed for appropriate use such as, communication, engaging in the situation, and helping the disabled on a more personal level to find the correct services they need to follow through with reporting the crime, establishing therapeutic treatment if necessary, and finding other services relative to their specific needs. The last policy implementation will generalize for all disabilities, but may be easier for some disabled to do than others. 


\section{Policy 3: Increasing Guardianship}

This policy will introduce and discuss mechanisms that will increase the guardianship, as it relates to routine activities theory, to decrease the likelihood of the disabled being perceived as vulnerable targets. To re-iterate, routine activities theory consists of three variables that must be present for a crime to occur; first is a suitable target, a lack in capable guardianship, and a motivated offender. Guardianship is established through changing your current involvement with a group of people, the setting at which you are present such as night club compared to someone's house, or the time at which you are traveling for example, night time versus day time.

The guardianship aspect is the most critical for the disabled due to this component being the only thing that a disabled person has some control over. For example, being a suitable target cannot be changed by itself. Being labeled and noticed as disabled automatically makes one become a suitable target. Furthermore, a suitable target or a disabled person neither has control of who is and who is not the motivated offender. Therefore, increasing what you have control of, guardianship, is the most important aspect by which to give special attention to.

How can you increase guardianship as a disabled person? There are several ways to increase the amount of guardianship one has in society. For example, a blind person can use a guide dog as a deterrent for an offender. This not only provides for accommodation to their everyday independent travel, but also serves as a symbol of protection over that particular blind individual. For a deaf person, a dog may not be a choice due to their accessibility needs or specifications, but a deaf person can still increase his group of friends when traveling, meeting someone new for the first time, or 
interacting with the general public. Joining different supportive organizations, such as the National Association of the Deaf, which can increase friendships and thereby enhance this aspect to take a full affect for the individual. Lastly, the discussion of "where" one spends time, parties, or generally commutes is important, in terms of controlling as much of the situation as possible.

The domain in which the disabled "hang out" with friends can be limited to household interaction amongst peers compared to any disabled person traveling alone to a party that involves being out late, being alone during the travel, and also the interaction one may encounter in the club. For example, a disabled person that is in a night club setting alone increases their chances of becoming more of a vulnerable target than they already may appear through possibly drinking, interaction with strangers, or continuing a party with a group of people by which one has recently been acquainted to that same day or night. This particular policy is not necessarily something that can be implemented into law, as we all have free will. However, these are measures that the disabled can take to avoid or at least increase their guardianship for their own safety. The following sections will provide a summarization of the material presented and conclude the potential improvements of safety of the disabled. 


\section{CHAPTER VII}

\section{SECTION 7: METHODOLOGY}

The prior discussion of victimization amongst the disabled population was gathered using a wide variety of intensive searching of combinations of terms online. Search engines such as Google, Proquest, JStor, and Google Scholar was the key engines by which searching were conducted. Through these different systems of searching a range of 150 to 225 different variances of terminology was used to narrow searches, define conceptually, perform political correctness to the search, and enhance potential for correlated information between victimization and disabilities. A list of the following is some of the search terms used, but is not the complete terms or contexts searched.

- Scholarly+disabled+crimes rates

- Crime rates+victimization+deafness

- Victimization amongst the disabled

- Legally blind victimization rates

- Scholarly blind victimization

- Medical journal of disabled victims

- Victim advocacy disabled

- Post disabled victim demographics

- Disabilities college victims

- $\quad$ Policy of disabled

- Public safety disabilities victimization rates

- Simple+violent crime rates on blind/deaf

- Post victimization resulting in disability

- Rehabilitation and disabled victims

- Blind victimology scholarly journal

- National Federation of the blind statistics

- Proquest victimization disability

- Disabled victims dissertations+Thesis

- CDC disability statistics

- Victimology of the disabled

- American Council for the blind statistics

- SES+Disabilities+caretaker abuse 
- Non-fatal victimization of blind and deaf

- ADA specifications for disability qualification

- National rates of disabled

No interviews, printed material, or surveys was used for collection of data. Most items used from the search terms resulted in journal articles of research varying from theses and dissertations. Others were enhanced research studies or Federal regulations for clarification of concepts used for example, activity limitation and disabled being SYNONOMOUS. The full list of online information will be found in the reference section at the end of this thesis. 


\section{CHAPTER VIII}

\section{SECTION 8: DISCUSSION}

Through review of the above mentioned research, there is valuable information that can potentially be used for further research, specifying research amongst diverse populations, and implementing possible tools in society to decrease the likelihood that a disabled person is victimized. The following will demonstrate the importance of the research and also the continuing knowledge there is to be done in the field of criminology. More explicit is the noted pattern in the research that has been conducted.

Through the studies involved in the above, a consistent finding is that of a disabled person being a victim at twice the rate than a non-disabled person. This is noticed through the disability research that generalized all disabled people into one category and stayed consistent through the research conducted for specific disabilities. For example, it has been shown through the Bureau Justice of Statistics, cited for the deaf and blind populations, both are consistent with being a victim of a crime at twice the rate of nondisabled individuals. Therefore, for the extending literature posed in the prior sections policy implementation and awareness for this population is important so as to decrease the chances of disabled persons being victimized. However, as also seen through this review there is a noticeable lack of information through the bodies of literature. 
Furthermore, this lack of information and research is something that needs to be addressed. Most important here is how few researchers have sustained and continued to conduct studies in various places, time frames, disability types, and types of victimizations that the disabled person may encounter compared to a non-disabled individual. Through the findings of research there was little information that indicated an importance for this issue to be addressed. However, to make this more of a necessity to research it is vital to recognize the following situations in which the victimizations occur, how they occur, and the offenders whom victimized disabled persons.

In addition, the occurrences at which these victimizations happen have been noted as being " $\{$ those $\}$ persons with disabilities are more likely than general crime victims to be victimized by someone they know, and less likely to be targeted by strangers," (BJS, 2010). In these situations the research also shows that "violent victimizations against all three disability groups are more likely to include a weapon, including gun, knife, and any other type of weapon" (BJS, 2010) and "Fully 33.4\% of disabled people report an injury requiring medical attention as a result of their violent victimizations, compared to only 27.7\% of non-disabled," (BJS, 2010). Combining those three aspects of the Bureau of Justice Statistics' findings there is a noticeable pattern of action when these victimizations present themselves. For example, a person who suffers from a disability who must have someone to take care of them or at least be a personal care assistant to their daily living on a regular basis should not also be subjected to potentially being victimized simply because they are disabled. To further the importance of this research there is a necessity to evaluate why a weapon is used on an already vulnerable 
population. This appears across victimizations of all disabilities in an independent living situation and also in an assisted living scenario.

Through my researching of literature, there appeared to be a larger section of deaf material that had more extended literature than other disabilities, but there is not a clear reason as to why this may be. For example, finding research of victimization for ambulatory, blind, and several other disabilities, the information preferred to group all disabilities into one category rather than extending the research one step further and individualize the needs that each disability needs or the differences in types of victimizations for those specific disabilities. Upon noticing this there is not a policy that fits to protect all individuals with disabilities. However, there are methods at which the importance can be analyzed to specify certain policies in the workforce, educational material, and other tools of awareness by which this can be improved. 


\section{CHAPTER IX}

\section{SECTION 9: CONCLUSION}

To conclude the evaluation of the disabled and their rate of victimization it is still a field which needs further exploration, but has an initial start. The information provided can and should be formally implemented through policy reform and educational collaboration. To also further analyze this particular topic the routine activity theory presents the most valued explanation for the victimization by the extension of the disabled being more suitable targets compared to the non-disabled. Therefore, this theory is the most efficient theory by which to breakdown the populations for further analysis of victimizations. Through furthering evaluation of research more policy recommendations can be promoted and could possibly prevent further victimizations through the findings for the disabled.

There is importance and need for the criminal justice field to explore further research into and how to decrease the victimization rates of the disabled By doing so there is more ability to further enhance the field to be more knowledgeable on the topic, integrate a more diverse population to research, and finally hold society accountable for treatment of the disabled, monitoring potential victims, and overall understand that being disabled does not group you into a single category. Instead, a focus of individualized material for different disabilities would allow others to see which disability is most vulnerable, care takers can be monitored if there is suspicion of victimization, and to add 
potential services to the disabled who have been through the struggles of victimization with nowhere or no one to report to for help or guidance. 


\section{REFERENCES}

American with Disabilities Act of 1990. 42 U.S.C. $§ 12102$.

Barrow, L. (2007). Silent victims: An examination into criminal victimization of the Deaf (Doctoral dissertation, City University, New York City). Retrieved March 7, 2015, from http://search.proquest.com/docview/304889345

Branic, N. (2014). Routine activities theory. In W.G. Jennings (Ed.), Encyclopedia of Crime \& Punishment. Malden, MA: Wiley-Blackwell.

Center on Victimization and Safety. (2013). In Vera Institute of Justice. Retrieved from http://www.vera.org/centers/victimization-and-safety

Cohen, L. E., \& Felson, M. (1979, August). Social Change And Crime Rate Trends: A Routine Activity Approach [Electronic version]. American Sociological Review, 44(4), 588-608. doi: 10.2307/2094589

Finkelhor, D., \& Asdigian, N. L. (1996). Risk Factors for Youth Victimization: Beyond a Lifestyles/Routine Activities Theory Approach. Violence and Victims, 11(1), 319.

Harrell, E. (2011, October). Crime Against Persons with Disabilities, 2008-2010Statistical tables. In National Crime Victimization Survey. Retrieved from http://www.bjs.gov/content/pub/pdf/capd10st.pdf

Office for Victims of Crime. (n.d.). Crime and Disability. In Promising Practices In Serving Crime Victims with Disabilities. Retrieved from http://www.ovc.gov/publications/infores/ServingVictimsWithDisabilities_bulletin /crime.html

Perreault, S. (2009, May). Criminal Victimization and Health: A Profile of Victimization Among Persons with Activity Limitations or Other Health Problems. In Canadian Center for Justice Statistics. Retrieved from http://www.statcan.gc.ca/pub/85f0033m/85f0033m2009021-eng.pdf

Reid, G. 2004. "Abuse of people with disabilities." Brochure d'information pour fournisseurs de services. The People's Law School. Vancouver 
Scherer, H. L. (2011). Disability Status and Victimization Risk among a National Sample of College Students: A Lifestyles-Routine Activities Approach (Doctoral dissertation, University of Cincinnati, Cincinnati). Retrieved from http://rave.ohiolink.edu/etdc/view?acc_num=ucin1311692494

Sigmon, J., \& Edmunds, C. (2002). Chapter 15: Victimization of Individuals with Disabilities. In OVC Archive: National Victim Assistance Academy Textbook. Retrieved from https://www.ncjrs.gov/ovc_archives/nvaa2002/chapter15.html

Smith, N., \& Hope, C. (2015, January 28). Culture, Language, and Access: Key Considerations for Serving Deaf Survivors of Domestic and Sexual Violence. In Vera Institute of Justice. Retrieved from http://www.vera.org/pubs/special/serving-deaf-survivors-domestic-sexualviolence

Summary of Crime Against Persons with Disabilities. (2013, March 7). In Sexual Violence Prevention and Education Program in Arizona. Retrieved from http://www.azrapeprevention.org/sites/azrapeprevention.org/files/Summary\%20of \%20Crime\%20Against\%20Persons\%20with\%20Disabilities.pdf

Tewksbury, R., \& Mustaine, E. (2010). Cohen, Lawrence E., and Marcus K. Felson: Routine activity theory. In F. Cullen, \& P. Wilcox (Eds.), Encyclopedia of criminological theory. (pp. 187-193). Thousand Oaks, CA: SAGE Publications, Inc. doi: http://dx.doi.org/10.4135/9781412959193.n52

The National Clearinghouse on Family Violence. (1993, February). Family Violence Against Women with Disabilities. In Health Canada. Retrieved from http://publications.gc.ca/collections/Collection/H72-22-9-1993E.pdf

The National Clearinghouse on Family Violence. (2004). Violence Against Women with Disabilities. Ottawa, ON: Government of Canada.

The 2006 Participation and Activity Limitation Survey: Disability in Canada . (2010, January). In Statistics Canada . Retrieved from http://www5.statcan.gc.ca/olccel/olc. action?objId=89-628-X\&objType=2\&lang=en\&limit=1

US Census Bureau. (1996). The Official Statistics - Disability Status of Persons (SIPP). US Census Bureau. Retrieved from http://www.census.gov/hhes/www/disable/sipp/disstat.html 


\section{CURRICULUM VITA \\ DEREK ALLEN}

\section{CURRENT POSITION}

Court Designated Worker

429 Muhammad Ali Blvd

Louisville, KY 40202

502-595-0036

derekallen@kycourts.net

\section{EDUCATION}

M.S. Department of Justice Administration, University of Louisville May 2015

Thesis title: "The Impact of Victimization on the Disabled."

Chair: Dr. Richard Tewksbury

B.A. Department of Psychology, University of Louisville

December 2012

B.A. Department of Political Science, University of Louisville

Minor in Justice Administration

December 2012

\section{RESEARCH INTERESTS}

- Victimization on the disabled

- Juvenile Delinquency

- Criminal Behavior

- Sex Crimes

- Cyber Crimes 